\title{
Impact of death and dying on the personal lives and practices of palliative and hospice care professionals
}

\author{
Shane Sinclair PhD \\ See related commentary by McGrath and Kearsley, page 169
}

Competing interests: None declared.

This article has been peer reviewed.

\section{Correspondence to:}

Dr. Shane Sinclair,

shane.sinclair

@albertahealthservices.ca

CMAJ 2011. DOI:10.1503

/cmaj.100511

\begin{abstract}
Background: Working within the landscape of death and dying, professionals in palliative and hospice care provide insight into the nature of mortality that may be of benefit to individuals facing the end of life. Much less is known about how these professionals incorporate these experiences into their personal lives and clinical practices.
\end{abstract}

Methods: This ethnographic inquiry used semi-structured interviews and participant observation to elicit an in-depth understanding of the impact of death and dying on the personal lives of national key leaders $(n=6)$ and frontline clinicians $(n=24)$ involved in end-of-life care in Canada. Analysis of findings occurred in the field through constant comparative method and member checking, with more formal levels of analysis occurring after the data-collection phase.

A lthough preserving life is a central goal of medicine, in the end, death is an unavoidable outcome. Professionals in palliative and hospice care, working within the landscape of death and dying, are able to provide insight into death-related experiences and have the opportunity to incorporate these experiences into their personal and professional lives. The ability for death to foster meaning in life has been attested to by wisdom traditions and palliative care professionals alike. The latter usually provide rich accounts of the struggles of dying individuals, and in some instances, accounts of individuals who discovered meaning and purpose within this landscape.

Although an expansive body of literature has evolved exploring the spiritual and existential impact of death and dying, these studies focused predominately on the impact on patients and occasionally on family members. ${ }^{1-5}$ A small number of studies discussed the residual impact of end-of-life care within a localized group of health care providers; however, there is limited cross-sectional research explicitly investigating
Results: Eleven specific themes, organized under three overarching categories (past, present and future), were discovered. Early life experiences with death were a common and prominent feature, serving as a major motivator in participants' career path of end-of-life care. Clinical exposure to death and dying taught participants to live in the present, cultivate a spiritual life, reflect on their own mortality and reflect deeply on the continuity of life.

Interpretation: Participants reported that their work provided a unique opportunity for them to discover meaning in life through the lessons of their patients, and an opportunity to incorporate these teachings in their own lives. Although Western society has been described as a "deathdenying" culture, the participants felt that their frequent exposure to death and dying was largely positive, fostering meaning in the present and curiosity about the continuity of life.

the long-term effect of death and dying on the personal and professional lives of individuals who are exposed to death and dying on a frequent basis. ${ }^{6-15}$

To address these gaps in the literature, this study explored the impact of death and dying on the lives of key leaders and frontline professionals in palliative and hospice care - individuals who arguably provide society and health care practitioners with the most authoritative discourse on end of life and its effect on life in general. This study was part of a larger ethnographic inquiry on the spirituality of palliative and hospice care professionals in Canada.

\section{Methods}

\section{Study population}

Data were collected in two phases. With the use of purposive sampling, six key leaders in palliative and hospice care at five centres across Canada were identified for the first phase of the study. The leaders were identified based on their 
contribution to the field of palliative and hospice care in Canada, on a clinical, research or policy level. One of the identified leaders declined participation because of a busy work schedule, which required an additional individual to be recruited. For the second phase of the study, a convenience sample of 24 frontline palliative and hospice care professionals at a hospice in the province of Alberta was identified. The length of time the leaders worked in palliative care was 19.8 years on average. The length of time the 24 frontline professionals worked in palliative care was 7.2 years on average.

The study sample consisted of a variety of professionals, including physicians, nurses, psychologists and spiritual care providers, reflecting the composition of an interdisciplinary palliative care team. As is characteristic of qualitative studies in general, the sample size was not predetermined but, rather, was developed until data saturation emerged, when I and an auditor (my doctoral supervisor) determined that no new data were being discovered. By being embedded in the culture over a long time, I was able to capture a holistic cross-sectional perspective, which allowed for the opinions of those who either did not express an initial interest or held a contrasting perspective on the topic to be included in the sample.

Each key leader consented to waive his or her anonymity (they are listed in the Acknowledgements section). This option was not available to the frontline clinicians, because frontline staff who wished to remain anonymous could be identified through a process of elimination.

\section{Data collection}

A qualitative ethnographic inquiry was conducted with the use of semi-structured interviews and participant observation, which allowed participants' experiences with death and dying to be recorded as they occurred in their clinical practice. The interviews were about two hours long and were conducted in a private space at the participant's place of work. Although an interview guide was constructed for consistency (Box 1), the process was open to allow for exploration of individual experiences. Interviews were audiorecorded and transcribed by a professional transcriptionist.

In the first phase, each leader was interviewed and observed in his or her clinical work for about a week. At the completion of the first phase, a preliminary analysis of the data was conducted over four months. In the second phase, the frontline professionals were interviewed and observed in their clinical work at the hospice.

Historically, ethnography has been defined as research "relating to a localized nation or race."16 Today, the term has evolved to include "a group of people who have something in common ... a work site, a lifestyle, a nursing home or a management philosophy"17 or "the art and science of describing a group or culture." ${ }^{18}$ The two primary techniques for data retrieval in ethnographic studies are interviews and participant observation. ${ }^{18-20}$ Interviews primarily provide ethnographers with the perspective of the insider - the emic perspective. ${ }^{20-22}$ Participant observation allows ethnographers to collect data primarily from an outsider's perspective - the etic perspective. ${ }^{23}$ Each informs the other dialectically. ${ }^{24}$ For this study, as a certified multi-faith spiritual care professional with the Canadian Association for Spiritual Care, I took the role of observer-asparticipant. ${ }^{25}$ This approach emphasizes a dialectical researcher-participant relationship and the social construction of knowledge - an approach that is congruent with philosophical assumptions of poststructuralism. The topic of study also influenced this approach, because the establishment of a trusting researcher-participant relationship was felt to be necessary to elicit the deeply personal views, beliefs and experiences of participants.

The time-intensive holistic character of ethnography allowed for the initial analysis of findings to occur in the field. Interviews, informal discussions and participant observations were validated in "real time" through the constant comparative method and member checking. Member checking involves inviting participants to clarify and confirm the researcher's initial interpretations of their data, which enhances credibility in the process. The constant comparative method allows for initial findings to be validated by participants in an ongoing manner, honing and expanding the researcher's cultural knowledge, and informing subsequent data collection in the process. ${ }^{19,22}$ Credibility was also enhanced by the auditor's examination of field notes and analysis of data, so that evidence of biases could be made explicit. Although no explicit

Box 1: Guiding questions used in the semi-structured interviews

- What does a typical day at work look like for you?

- What drew you to palliative care?

- Do you have a sense of fulfillment working in palliative care?

- What is spirituality?

- Have you had what you would consider a "spiritual experience" in your work or life?

- Describe, if applicable, how your own spirituality connects with patients?

- Have your patients influenced your own spirituality? If so, how? 
biases were noted, some codes were modified through the member checking and auditing process.

In addition to the analysis in the field, a more formal analysis was conducted after the datacollection phase. All interviews and field notes (written and audio-recorded) were evaluated independently by the auditor and me to get an overarching sense of the data, with initial notes jotted in the margins. This was followed by a secondary level of analysis, in which codes, or units of meaning, were developed as transcripts and field notes were read line by line. Codes were then organized into themes and categories, which were continually refined as areas of commonality and divergence were identified. The interpretation of themes was verified through member checking when necessary.

This study was approved by the Conjoint Health Research Ethics Board of the University of Calgary, the Ottawa Hospital Research Ethics Board and the Fraser Health Research Ethics Board.

\section{Results}

After the data from both cohorts were collected and aggregated, the impact of death and dying on the participants' personal and professional lives was organized temporally around three overarching categories (past, present, future) containing a total of 11 themes derived from the study data (Box 2).

\section{The past: the prominence of death in the early years}

If participants were united in a single experience early in life, it was the prominent role of death in their histories. Participants frequently cited these early experiences with death and dying when

Box 2: The overarching categories and themes derived from the study data

Past: the prominence of death in the early years

- Early integrated deaths

- Early disintegrated deaths

Present: the power of death over life

- Living in the present: practising dying

- Wholeness: spiritual integration

- Moving from head to heart: cultivating spirituality

- Integrated deaths in end-of-life care: lessons for life

- Disintegrated deaths in end-of-life care: sources of distress

Future: the continuity of life and death

- Good deaths: personal wishes

- Dying well: remaining curious and embracing death

- Living well: alleviating death-related anxiety

- The continuity of life: beliefs in life after death referring to their current work in palliative care, establishing what has been termed "a history of the present." ${ }^{26}$ The experiences with death and dying in the early years were divided into two themes: integrated deaths (the palliative care notion of a proverbial "good death") and disintegrated deaths (antithetical to "a good death"). ${ }^{27-29}$

Personal experiences with death and dying predated, and were often seen as an essential motivator to, participants' professional practice with terminally ill patients. Participants often relived these experiences, developing a rapport with death that in some sense could be described as an ongoing relationship. Their early experiences with death and dying were formative ones that shaped their understanding of their own life, giving them a sense of vocation and impelling them toward selfdiscovery (Box 3).

\section{Early integrated deaths}

For a number of participants, the prominence of death and dying in their own histories was a positive experience, where death and dying was acknowledged, normalized and integrated into the continuum of life (Box 3). Whereas disintegrated deaths left participants with a feeling of ontological discord, knowing that this was not the way things were ultimately meant to be, integrated deaths involved end-of-life experiences that were described as peaceful and a natural process to be accepted and not feared.

\section{Early disintegrated deaths}

Although participants described many of their early experiences with death as having been openly and effectively dealt with by their families, a number of participants felt that these critical incidents centred on a lack of acknowledgement and integration. Whether this was because of their families' inability to discuss death, or inappropriate and insensitive medical interventions in endof-life care during their medical training, disintegrated deaths occurred when death was partitioned from the rest of life (Box 3).

\section{Present: the power of death over life}

Exposure to death and dying had a strong influence on the participants' present life. Participants reported that end-of-life experiences positively transformed the way they lived their lives, teaching them to live in the present, cultivate a spiritual life and reflect deeply on the continuity of life (Box 4). Five themes emerged in this category.

\section{Living in the present: practising dying}

The practice of integrating dying into everyday life was another by-product of reflecting on 
one's mortality. Mortality was not seen by participants simply as an event at the end of life but, rather, as an ever present, moment-by-moment reality embedded across the continuity of life. "Practising dying" involved recognizing the impermanent nature of their own lives and the world they lived in. This manifested as an acceptance of their aging bodies and the loss of roles, and acknowledging the frailty of life (Box 4).

\section{Wholeness: spiritual integration}

Working in end-of-life care caused participants to ask themselves the same questions about the meaning and purpose of life that their dying patients were reflecting on. For participants, this cultivated and enhanced a sense of spirituality. Spirituality was collectively defined as an invisible connection between participants and the essence of one's self, other (another individual) or Other (a higher power/God), thereby affecting one's sense of wholeness within oneself and an ultimate reality. Whether experienced through practice or in their everyday interactions, these connections cultivated a deep sense of wholeness within participants. Wholeness was understood primarily as the cohesion of multifaceted aspects of themselves within a unified, interconnected concept of self. These aspects of themselves were diverse in composition, containing all facets of personhood, ranging from compassion to apathy, joy to sorrow, hope to despair, faith to disillusion, and cohesiveness to fragmentation (Box 4).

\section{Moving from head to heart: cultivating spirituality}

The cultivation of a spiritual life was not characterized by participants' disavowing critical aspects of their personality but, rather, by becoming aware of their existence and their power in selfperception and outlook in life. In contrast to this multifaceted perspective they came to know, participants felt that their perspective early in life was largely cerebral in nature. Instead of an objective, unidimensional perspective, working in end-of-life care caused them to process with their hearts, opening a world of contrast and mystery. This shift was often described as an inner awakening, fostering an acceptance of the unknown and a new way of seeing the world. In contrast to the cerebral life, moving to the heart was characterized by a shift from a life directed by outer authority to one directed by inner authority; a shift from a life of answers to one of questions; from scientific certainty to an openness toward life's mysteries; and from emotional detachment to integration (Box 4).
Integrated deaths in end-of-life care: lessons for life

Although some deaths in palliative and hospice care did not meet the ideal goal of "a good death," ${ }^{30}$ participants' clinical experiences with

\section{Box 3: Past: the prominence of death in the early years}

\section{Category: Past: the prominence of death in the early years}

- "For many years I kept a vial of cyanide in my desk. ... So death has been a companion of mine for most of my life.... I would say from the time I was a teenager, I was attracted to the idea of death as a way out, and it's only been in recent years, at least in the last ten years or more, that that's no longer been a background issue for me." - palliative and hospice care professional*

- "Shortly before I got there [medical school], I experienced two very significant deaths. ... So I think that superficially it [my interest in palliative care] was the death of my father-in-law and the death of my roommate, combined with my interest in combining humanities with medicine. ... I think that also I had a fair number of deaths in my family through my childhood, so I had more exposure to death." Key Leader 3

- "Then, as an intern, I had cancer, and that was a significant experience and a long story in itself, but it had a high mortality rate at that point .. so that was a major time in my life, and that certainly deepened my spiritual experience." - Key Leader 1

- "Death was always a part of my life. ... I still think I have probably a huge fear of death — I suspect that's partly what drew me into this field." Key Leader 4

\section{Theme: Early integrated deaths}

- "I can't remember how long it had been that she [great aunt] wasn't responsive and all she said under her breath was 'Sweet Jesus take me home, sweet Jesus take me home, sweet Jesus take me home.' And all of a sudden it was silent ... so I gently closed her eyes and I gave a kiss on her cheek and then I just sat back down. It didn't even faze me, I knew she died. ... I remember that was just so interesting, the most important person in my life has died and nothing changes." - Nurse J

- "Well, my father had died but we weren't with him at the time. I mean he was unwell and we had gone away for a picnic and I had brought my mom back home and he had died in his chair. And again that was God's hand because he did it on his own terms, and he thought, I know that he would have thought it would be too hard for my mom if she'd been there by herself to come across him sitting in his chair." - Nurse E

\section{Theme: Early disintegrated deaths}

- "Well, my mother died when I was six, and that was obviously a devastating experience. It affected my whole life, the way it was handled. We weren't allowed to acknowledge it; I don't remember my mother at all. I have no memory whatsoever. Except on her deathbed, when after she died, I saw her body. That's the only memory I have of my mother." - Key Leader 6

- "Well, I remember as probably a third- or fourth-year medical student, having been on the wards for a bit and I got to know this particular patient who was a blind man. When they opened him up, they found he had huge cancer in the stomach and he was inoperable, so they stitched him up and I kind of knew this. I kind of got to know him pretty well and I knew that on this particular morning he was awake after the surgery and he was waiting to hear how his operation had gone. ... We were at the bed before him and then the entourage moved on, waltzed completely past his bed and went on to the next patient and kept going, and he was just listening and waiting and I was sort of hanging out at the back of the group, and I remember the kind of feeling ... the feeling that I was very upset by that and it pained me in my heart." - Key Leader 2

*Because of the particularly sensitive nature of this quote and a subsequent discussion with the participant, further measures to ensure anonymity were taken, resulting in this generic descriptor. 
death and dying were predominantly described as positive. In talking about the moment of death and the time immediately preceding it, participants were quick to draw on stories of mystery that they felt privileged to be involved in and that helped to form their own beliefs in the continuity of life. Many participants believed that an aura of mystery was ever present at the time of death, whether or not they could clearly perceive its existence. Hospice nurses in particular spoke of a "near-death awareness," where they intuitively knew that death was imminent (Box 4).

\section{Disintegrated deaths in end-of-life care: sources of distress}

The majority of participants described their clinical experiences with death using terms such as "peaceful," "beautiful" and "good." However, there were also a number of accounts of the ugliness of death, which in turn mitigated a romanti-

\section{Box 4: Present: the power of death over life}

\section{Category: Present: the power of death over life}

- "Palliative care has been very precious to me. It has shown me what is important in life. What I can let go of." - Key Leader 4

- "I was drawn to the curiosity of what is depression, what is death." - Key Leader 3

\section{Theme: Living in the present: practising dying}

- "I practise dying every day. ... For the most part I'm just very aware this could be it and is there anything today I want to do? And it's just fleeting, it is not even five minutes, it is just a bit." - Nurse J

- "How do I want to die? I already have died in some regard, and I want that to be my teacher." - Key Leader 3

- "Working in palliative care has placed existential questions front and centre." - Key Leader 1

- "I think I am called to live more deeply [as a result of working in palliative care] because we are reminded about what a gift life is and all that has been entrusted to us." - Chaplain 2

\section{Theme: Wholeness: spiritual integration}

- "To explore and think about and be in the mystery and the depths and the moment and to celebrate the bad and the good that brings us to consciousness." - Key Leader 1

- "I realized that they [dying patients] had the courage to do what I hadn't done. ... I think that [wholeness] is the key. ... What matters is a sense of connection in the core of your being with something bigger than ourselves. ... It has to do with connection to self, 'other' with a small 'o' and connections to others with a capital 'O.' " - Key Leader 3

- "Palliative care draws people who are searching. ... Fear of death partly drew me to palliative care." — Key Leader 4

Theme: Moving from head to heart: cultivating spirituality

- 'Jon Kabat-Zinn has a phrase that describes 'dropping in' and if there's ever too much energy or too much distress, or too much angst, somebody's just cut me off in the car and I get ready to throttle them, I think of this little comment, 'Let's drop in right now,' and dropping in has to do with consciously moving, symbolically and metaphorically, from head to heart." — Key Leader 1

- "That's become very important to me, that concept that we are co-creating something together ... that within each healer is a patient and within each patient is a healer." - Key Leader 5

- "I've never stopped to even ask some of those questions. ... She [the patient] was a profound teacher in terms of looking at your sense of self." - Key Leader 3

- "I think that the unknown is what causes great dis-ease for people. ... We don't have the answers, and to pretend that we do would be arrogant. ... I think I am more comfortable with, or less uneasy with the unknown, I'm willing to trust. ... God is everywhere and I mean if we have the eyes and the open hearts to the working of the spirit ...." — Chaplain 2

\section{Theme: Integrated deaths in end-of-life care: lessons for life}

- "He [patient] said, 'Yeah, I'm going to die today.'... There was no way that he should die ... and he died within forty-eight hours. I marvel at that. ... There's a mystery there." - Key Leader 3

- "I woke up in the night and I knew that she had died. I didn't feel sad, I didn't feel alarmed, I felt calm." — Nurse E

- "She [patient] said to me 'Tell my children I can see them playing on the snow, and I know I am never going to see them again, but tell them, I'm going to be part of a heavenly team.' " - Key Leader 5

- "She [patient] had a little bit of a frown on her face, and I said 'Peace be with you and go now in peace' and I said her name, and she was gone just like that." — Chaplain 2

- "I went back into the resident's room and I called her by name and I said 'Do you know something that I don't know?' and she opened her eyes, looked at me and said 'A lot.' She closed her eyes, put her head back, and she died six hours later." — Nurse J

\section{Theme: Disintegrated deaths in end-of-life care: sources of distress}

- "It was pretty sad because she had two young children and the husband went home to get the girl all dressed in her pretty dress. He wanted them to look nice for their mother who had already died." — Nurse E

- "... and he never got through the anger." - Key Leader 3

- "I smelt the wound before I saw it - a raw piece of flesh. The odour was unpleasant, my nose flinched, my jaw locked as the smell of rotting flesh entered my nostrils. This is the reality of palliative care — it's ugly." — author [field journal]

- "[When family dynamics exist] the resident does not feel as peaceful and take longer to die." — Nurse E 
cized perspective of mortality. Although these deaths occurred less frequently than their tranquil counterparts, they made an equal impression on participants. In conducting the fieldwork, I found that the sights, smells and harshness of death, ranging from open wounds to phlegm-filled hacking, stood in stark contrast to the predominance of meaningful deaths that occurred. Deterioration and disintegration often extended beyond the physical domain to include the emotional, social and spiritual domains of suffering, wherein achieving a sense of peace and finding meaning and reconciliation were often unattainable within the time allotted. These deaths, marked by the absence of loved ones and the inability to control suffering, constituted the most difficult experiences with death that the participants recalled (Box 4).

\section{Future: the continuity of life and death}

As a result of providing clinical end-of-life care, the majority of participants reflected on their own death and dying. These lessons, provided by patients themselves, caused participants to vicariously rehearse their own dying through the deaths of their patients. Participants felt that facing one's mortality, initially a daunting exercise, was ultimately beneficial and perhaps a necessary prerequisite to caring effectively for dying individuals (Box 5).

\section{Good deaths: personal wishes}

Participants expressed a number of hopes regarding how they would like to die. Awareness of death, maintenance of meaning, remaining selfcongruent, participating fully in their dying, and being at peace with loved ones were the core elements of participants' personal concepts of what would constitute a good death (Box 5).

\section{Dying well: remaining curious and embracing death}

Although they expressed hopes surrounding the nature of their death, most participants acknowledged the importance of remaining open to the possibility that their death may not unfold as anticipated. This perspective came from experiences of dying individuals, who became deeply disappointed when their expectations of their final moments failed to materialize. Participants acknowledged that death was often unpredictable and mysterious, cautioning them against forming fixed, preconceived notions of how death would unfold. Anticipating one's death involved reflecting not only on acceptable death scenarios, but also on scenarios that were less acceptable, thereby gaining greater acceptance of one's mortality (Box 5).

\section{Living well: alleviating death-related anxiety}

Reflecting on their own mortality provided participants a clearer perspective on what is important in life, an increased acceptance surrounding the uncertainty of death and a diminished fear associated with dying. Eliminating deathrelated fear and anxiety was not the goal of reflection and was felt to be an unrealistic expectation by participants. This process of confronting their fears did not mitigate participants' death-related anxiety; rather, it expanded their capacity to face such fears in the future (Box 5).

\section{Box 5: Future: the continuity of life and death}

\section{Category: Future: the continuity of life and death}

- "The notion of being curious at the time of one's death was something that had a lot of appeal for me. ... If one can at least go to one's death curious about what lies beyond, then death doesn't have the same finality that it has if we think that this is it." -Key Leader 4

- "I think in order to be with people who are dying, you have to face your own mortality. ... I don't know if there's any other place where, on a daily basis, we are facing death." - Nurse J

\section{Theme: Good deaths: personal wishes}

- "I want to be able to live to be 100 , but if I get to be 85 or 90 I'll be able to say it has been a good life. ... I want to live with integrity and want to die with integrity." - Key Leader 3

- "I want to know that I am going to die. ... I hate the idea of being sedated. Mindfulness at the moment of death is what determines the next time. ... My goal is to try and maintain my mindfulness as long as possible." - Key Leader 4

\section{Theme: Dying well: remaining curious and embracing death}

- "I even say to my husband 'I will haunt you until eternity if you say that "she died a peaceful death" and I was thrashing.' " - Nurse J

- "We [palliative and hospice care professionals] all have those conversations 'What if it were me?,' but when it is you, it is not like you thought it would be." - Key Leader 3

Theme: Living well: alleviating death-related anxiety

- "Each experience compounds the last. I'm not afraid of death and I'm not afraid to help a family be with their loved one at the end-of-life." Nurse E

- "I typically don't fear dying. ... I can think of my husband, and I can think of my children. I don't need to see a wedding and those things or a graduation." - Nurse J

\section{Theme: The continuity of life: beliefs in life after death}

- "It is just a strong sense that beyond physical life there is still a presence, you know, just a presence." - Nurse J

- "I like the Buddhist notion of some kind of rebirth." - Key Leader 4

- "I won't see her [late sister] again as a physical entity." - Key Leader 3

- "One of the first things I do when I get in the car is say 'All right guys [deceased patients and family members], I'm not dead you know. Keep getting me into work safe.' " - Nurse J

- "I had my CAT scan appointment for this particular day and I was aware that all the people that I had worked with over the years [were there]." - Key Leader 5

- "Maybe we will see one another." - Assistant 2

- "I think we are the saints, and I think we'll all be saints." — Volunteer 2 
The continuity of life: beliefs in life after death

Although participants reported that mysterious and numinous experiences happened infrequently, their occurrence was foundational to participants' belief in the continuity of life. Numinous experiences, although interpreted through various means, including different faith traditions, were central to participants' belief in life after death. These experiences did not provide certainty about the specific nature of this reality, only curiosity and a belief in its existence. Being curious was a central feature of believing in the continuity of life, because these experiences affirmed an existence that remained outside of their comprehension. The majority of participants saw life after death as a spiritual and nonphysical existence, although they maintained a belief that the spiritual could sometimes manifest within the physical domain (Box 5).

\section{Interpretation}

The impact of death and dying on participants' personal lives has many implications, both within and beyond palliative care. Although Western society has been described as a "deathdenying" culture, ${ }^{29}$ participants reported that their exposure to dying patients was largely a positive experience. It provided a contrast whereby greater meaning in life, spirituality, self-discovery and beliefs in the continuity of life could flourish.

Participants' frequent exposure to death and dying provided an authoritative perspective to the eyewitness accounts of the diverse experiences of individuals facing the end of life. Despite a number of accounts of the ugliness of death, the end of life was consistently described by participants as a meaningful stage of life, which may have a beneficial effect in diminishing death-related anxiety and fear. Participants' acknowledgement and integration of death into their lives not only normalized death but also heralded enhanced meaning in life. Spirituality functioned as a framework for meaning ${ }^{31-34}$ that helped participants make sense of the end of life and enhanced their present life in the process. Death's influence on participants' spirituality was informed not only by positive features of joy, peace and meaning, but also by experiences of suffering, despair and disillusionment.

This study offers hope for individuals facing the end of life. It also raises many salient questions, including why, if death and dying is described as a meaningful stage of life by those who work in palliative care, do so many people fear it so intensely? The reports from participants suggest that individuals' fears about death and dying rarely materialized. Addressing mortality prospectively seemed to dissipate anxiety associated with this stage of life and, according to most participants, enhanced meaning in life in the interim. Health care professionals may benefit from the opportunity to acknowledge, normalize and integrate death and dying into the continuum of life, both for themselves as well as their patients. Remaining oneself $\mathrm{f}^{35}$ and attempting to participate fully in death and dying were essential features of participants' notion of dying well, with beliefs in the afterlife providing a supportive, but secondary function. The field of palliative care is well served when attention is paid to the physical as well as the spiritual dimensions of end of life. Whether in reference to education, research or clinical care, this duality can promote well-being and personal growth for patients and health care providers alike.

The findings from this study are consistent with those of previous studies that described the impact of end-of-life care on the personal and professional lives of health care providers. ${ }^{6-15}$ They are also comparable to findings from studies in which end-of-life experiences presented many challenges to health care providers but were secondary to the numerous beneficial aspects of their work, especially as they related to meaning and purpose. . $7,7,11,14,32^{2}$ This study differed from others in its explicit focus on the impact of death and dying on health care providers; its cross-sectional sample of national leaders and frontline professionals in palliative and hospice care; and the inclusion of participants' experiences with death and dying across the trajectory of their lives.

\section{Limitations}

This study has several limitations. The perspectives of the study population, although a unique and critical perspective on the impact of death and dying on the personal and professional lives of professionals in palliative and hospice care, likely differ from the perspectives of professionals outside of palliative care, including those who chose to leave the field. Furthermore, in volunteering to participate in this study, participants were likely comfortable with the topic of spirituality in general, and the topic of death and dying specifically. Finally, although this qualitative study included a cross-section of national leaders in palliative care, the study may not be generalizable. Further research is required in in Canada and elsewhere, including sampling areas where palliative care programs may not be as readily available. 


\section{Conclusion}

Although one might assume that repeated exposure to death and dying would have mostly a negative impact on the lives of professionals in palliative and hospice care, this study showed the opposite. Participants attested to the weighty nature of their vocation, but this was far outweighed by the many affirming life lessons that participants incorporated into their own lives and practices. Participants felt that they occupied an opportune place to discover meaning in life - sitting at the bedside of those nearing death. They had the opportunity to incorporate these truths into their everyday lives, integrating end-of-life wisdom from the vantage of foresight, in contrast to the perspective of dying patients looking back on their lives. Although the end of life is arguably the most challenging phase of life, it may also be the most meaningful, providing hope to those who are living with an incurable illness as well as individuals who will inevitably face their mortality in the future.

\section{References}

1. Sinclair S, Pereira J, Raffin S. A thematic review of the spirituality literature within palliative care. J Palliat Med 2006;9:464-79.

2. Hebert RS, Schulz R, Copeland VC, et al. Preparing family caregivers for death and bereavement. Insights from caregivers of terminally ill patients. J Pain Symptom Manage 2009;37:3-12.

3. Holtslander LF, Duggleby W. The experience of hope for informal caregivers of palliative patients. J Palliat Care 2005;21: 285-91.

4. Holtslander LF, Duggleby W. The hope experience of older bereaved women who cared for a spouse with terminal cancer. Qual Health Res 2009;19:388-400.

5. Steinhauser KE, Christakis NA, Clipp EC, et al. Factors considered important at the end of life by patients, family, physicians, and other care providers. JAMA 2000;284:2476-82.

6. Bailey ME, Moran S, Graham MM. Creating a spiritual tapestry: nurses' experiences of delivering spiritual care to patients in an Irish hospice. Int J Palliat Nurs 2009;15:42-8.

7. Boston PH, Mount BM. The caregiver's perspective on existential and spiritual distress in palliative care. J Pain Symptom Manage 2006;32:13-26.

8. Daaleman TP, Usher BM, Williams SW, et al. An exploratory study of spiritual care at the end of life. Ann Fam Med 2008;6: 406-11.

9. Holland JM, Neimeyer RA. Reducing the risk of burnout in end-oflife care settings: the role of daily spiritual experiences and training. Palliat Support Care 2005;3:173-81.

10. MacConville U. Mapping religion and spirituality in an Irish palliative care setting. Omega 2006;53:137-52.

11. Millison MB. Spirituality and the caregiver: developing an underutilized facet of care. Am J Hosp Care 1988;5:37-44.

12. Millison MB, Dudley JR. The importance of spirituality in hospice work: a study of hospice professionals. Hosp J 1990;6:63-78.

13. O'Connor P, Kaplan M. The role of the interdisciplinary team in providing spiritual care: an attitudinal study of hospice workers. In: Wald F, editor. In quest of the spiritual component of care for the terminally ill. New Haven (CT): Yale University Press; 1986. p. 51-62.

14. Sinclair S, Raffin S, Pereira J, et al. Collective soul: the spirituality of an interdisciplinary team. Palliat Support Care 2006;4:13-24.

15. Vance D. Nurses' attitudes towards spirituality and patient care.
Medsurg Nursing 2001;10:264-8.

16. Hoad T. Oxford concise dictionary of English etymology. New York (NY): Oxford University Press; 1996.

17. Boyle J. Styles of ethnography. In: Morse JM, editor. Critical issues in qualitative research methods. Thousand Oaks (CA): Sage; 1994. p. 159-85.

18. Fetterman D. Ethnography: step by step. Newbury Park (CA): Sage; 1983

19. Atkinson P, Hammersley M. Ethnography: principles in practice. 3rd ed. London (UK): Routledge; 2007.

20. Atkinson P, Coffey A, Delamont S, et al., editors. Handbook of ethnography. London (UK): Sage; 2002.

21. Morse JM. Qualitative nursing research: A free for all? In: Morse J, editor. Qualitative nursing research: a contemporary dialogue. Revised edition. Newbury Park (CA): Sage; 1991. p. 14-22.

22. Germain C. Ethnography: the method. In: Munhall P, Oiler Boyd C, editors. Nursing research a qualitative perspective. New York (NY): National League for Nursing; 1993. p. 237-68.

23. Morse JM, Field P. Qualitative research methods for health professionals. Thousand Oaks (CA): Sage; 1995.

24. Anderson JM. Reflexivity in fieldwork: toward a feminist epistemology. Image J Nurs Sch 1991;23:115-8.

25. Junker B. Field work. Chicago (IL): University of Chicago Press; 1960.

26. Foucault M. Discipline and punish: the birth of the prison. New York (NY): Vintage Books; 1975.

27. Walter T. Historical and cultural variants on the good death. $B M J$ 2003;327:218-20.

28. Walters G. Is there such a thing as a good death? Palliat Med 2004; $18: 404-8$

29. Zimmermann C, Rodin G. The denial of death thesis: sociological critique and implications for palliative care. Palliat Med 2004; $18: 121-8$

30. Saunders C, Summers D, Teller N. Hospice: the living idea. London (UK): Edward Arnold; 1981.

31. Chochinov HM, Hassard T, McClement S, et al. The landscape of distress in the terminally ill. J Pain Symptom Manage 2009; 38:641-9.

32. Desbiens JF, Fillion L. Coping strategies, emotional outcomes and spiritual quality of life in palliative care nurses. Int J Palliat Nurs 2007;13:291-300.

33. Clark L, Leedy S, McDonald L, et al. Spirituality and job satisfaction among hospice interdisciplinary team members. J Palliat Med 2007; 10:1321-7.

34. Strang S, Strang P. Spiritual care. In: Bruera E, Higginson I, Ripamonti $\mathrm{C}$, et al., editors. Textbook of palliative medicine. London (UK): Hodder Arnold; 2009. p. 1019-28.

35. Chochinov HM, Hassard T, McClement S, et al. The patient dignity inventory: a novel way of measuring dignity-related distress in palliative care. J Pain Symptom Manage 2008;36:559-71.

Affiliations: Shane Sinclair is a Canadian Institutes of Health Research postdoctoral fellow in the Manitoba Palliative Care Research Unit, University of Manitoba, Winnipeg, Man.; an adjunct lecturer in the Department of Oncology, Division of Palliative Medicine, Faculty of Medicine, University of Calgary, Calgary, Alta.; and the spiritual care coordinator with Alberta Health Services, Tom Baker Cancer Centre, Calgary, Alta.

Funding: This work was supported through a Canadian Institutes for Health Research-Wyeth Pharmaceuticals postdoctoral fellowship at the University of Manitoba.

Acknowledgements: This article is dedicated to the late Dr. John Seely, a giant of a man in both stature and presence. The author thanks all of the participants in this study, including the key leaders Dr. Balfour Mount, Dr. Michael Kearney, Dr. David Kuhl, Dr. John Seely, Dr. Mary Vachon and Jeremy Wex. The author also thanks Drs. Harvey Max Chochinov, Neil Hagen, Susan McClement and Shelley Raffin (doctoral supervisor) for their guidance in this study. 